\title{
A POBREZA COMO DESRESPEITO À DIGNIDADE HUMANA: UMA ANÁLISE DA EFETIVIDADE DO BOLSA FAMÍLIA NO BRASIL
}

\author{
Soraya Braga de Sousa Dantas ${ }^{1}$ \\ Hertha Urquiza Baracho
}

\section{Resumo}

A erradicação da pobreza é um dos objetivos primordiais da constituição federal. Os direitos sociais devem ser concretizados pelo Estado através da implementação de políticas públicas eficientes e capazes de propiciar a todos, sem distinção, o gozo de uma vida digna. Este artigo tem por escopo provocar uma reflexão a respeito da pobreza e analisar a efetividade do programa social de transferência de renda, o Bolsa família. Nesta esteira, adota-se o método de abordagem dedutivo, com pesquisa descritiva e emprego de dados bibliográficos e documentais.

Palavras-chave: Pobreza. Dignidade Humana. Mínimo Existencial. Direitos Sociais. Bolsa Família.

\section{THE POVERTY AS A DISRESPECT TO THE HUMAN DIGNITY; AN ARTICLE ABOUT THE "BOLSA FAMÍLIA" IN BRAZIL}

\begin{abstract}
The poverty erradification is one of the most primarys objectives of the Federal Constituition. The social rights have to be fulfilled by the State, over a push on the implementation of public policies capable of giving, without no descrimination, the enjoyment of a decent life. This article aims to seek a respectful reflection about the poverty, with an strong view of one of the most controversial social economic programs in Brazil's history, the Bolsa Família To this article, the method adopted was the use of bibliographical dades and documentarys, as an descriptive research.
\end{abstract}

Keywords: Poverty. Human Dignity. Minimum existential. Social Rights. Bolsa Família.

\footnotetext{
${ }^{1}$ Bacharel em Direito pela UNIPÊ. Adovada (OAB 17630). Especialista em Ciências Criminais Anhanguera/SP. Mestranda em Direito e Desenvolvimento Sustentável - PPGD/UNIPE.

2 Pós-Doutorado na Università degli Studi di Firenzi, UNIFI, na área da Ciências Sociais Aplicadas. Doutora em Direito do Estado (Área de concentração Direito Constitucional) pela PUC/SP. Mestre em Direito do Estado (Área de concentração Direito Constitucional) pela PUC/SP. Professora do Centro Universitário de João Pessoa UNIPÊ. Coordenadora do Grupo de Pesquisa: Relações Empresariais: função social e responsabilidade Social das Empresas.
} 


\section{INTRODUÇÃO}

O ser humano tem o direito de nascer e também de viver com dignidade, por isso, é confiado ao Estado a tarefa de garantir que esses direitos sejam respeitados e que desta forma o bem estar social seja promovido.

Os direitos humanos pertencem a qualquer ser humano, o que comprova sua universalidade, pois independe de sua origem, gênero, religião, ou qualquer condição que venha de alguma forma segregá-lo. Assim, estes direitos são atingidos pelo problema da pobreza que passa a ser uma preocupação mundial.

O assunto pobreza no Brasil não é algo novo. Desde os primórdios, as desigualdades sociais fazem parte da história deste país que, embora seja famoso por apresentar riquezas naturais extraordinárias, seu povo sofrido luta pela sobrevivência dia após dia.

O presente artigo faz-se importante na medida em que levanta a questão da pobreza como um convite a uma reflexão acerca deste tema tão sensível e que engloba uma série de princípios constitucionais que são mormente desrespeitados. A problemática gira em torno da discussão sobre a real eficácia dos programas de transferência de renda para aqueles que pertencem às camadas sociais mais pobres, se seria, a implementação do programa bolsa família, a melhor solução para erradicação da pobreza.

Depois de inúmeras lutas e reivindicações ocorridas ao longo do tempo à procura de realizar o bem estar social, o povo brasileiro viu na constituição de 1988, o manto protetor do homem. Para que ele exerça sua cidadania, goze de sua liberdade plenamente, é preciso que haja, em primeiro lugar, a satisfação de suas necessidades mínimas.

A proteção estatal se concretiza com a implementação de políticas públicas capazes de minimizar a pobreza no país. São exemplos: o oferecimento de uma saúde pública de qualidade; a promoção de uma educação ao alcance de todos com a finalidade de extinguir o analfabetismo; assumir papel ativo ao possibilitar assistência social; incentivar a criação de novos empregos; entre outros.

Torna-se relevante, a busca das melhores soluções a partir da análise da pobreza como fator que suscita a violação dos direitos sociais resguardados pela Carta Magna. Compreender o papel dos programas de transferência de renda, em especial o bolsa família, e entender a questão da promoção do mínimo existencial como forma de preservar a dignidade da pessoa humana são objetivos desse trabalho.

Rev. de Direito Sociais e Políticas Públicas| e-ISSN: 2525-9881| Maranhão | v. 3 | n. 2 | p. 1 - 17 | Jul/Dez. 2017. 
Para tanto, são adotados procedimentos metodológicos para assegurar o caráter científico do presente artigo, tais como, a nomeação do método de abordagem dedutivo, posto que, analisa-se a pobreza, o princípio da dignidade da pessoa humana, o instituto do mínimo existencial e os direitos sociais, para então, compreender a eficácia do programa de transferência de renda a partir de condicionantes adotadas para melhorar a qualidade de vida da população. Elegeu-se uma pesquisa descritiva sobre o tema com o emprego de dados bibliográficos e documentais.

\section{POBREZA: DEFINIÇÃO E CONSIDERAÇÕES}

A pobreza, normalmente está atrelada à definição de escassez de bens materiais que comprometem o bem estar social. É oriunda das desigualdades sociais marcantes e típicas de países em desenvolvimento.

Há na doutrina uma abordagem que divide a pobreza em níveis, ou seja, em graus que constatam as condições em que as pessoas vivem, considerando-se as privações de necessidades básicas.

A pobreza, quando dita extrema, nos revela a ausência de recursos que comprometem a própria existência humana, posto que, neste caso, a falta de alimentação, por exemplo, pode levar à morte. A ausência de artigos imprescindíveis à manutenção da vida é algo extremamente preocupante, assim, a erradicação da pobreza é assunto discutido em todo o mundo.

No caso da pobreza moderada, com muito esforço, as necessidades vitais são alcançadas. Já com relação à pobreza relativa, apesar de satisfeitas suas necessidades mínimas, os indivíduos, dentro do seu contexto, do seu convívio social, apresentam-se em uma situação inferior, nível este mais analisado e compreendido no âmbito dos países desenvolvidos.

\footnotetext{
Pobreza extrema ou miséria significa que as famílias não podem satisfazer as necessidades básicas de sobrevivência. Elas sofrem de fome crônica, não têm acesso à saúde, não dispõem de água potável e esgoto, não podem oferecer educação para alguns ou todos os filhos e talvez não tenham um abrigo rudimentar - um teto para proteger da chuva, uma chaminé para tirar a fumaça do fogão - e artigos básicos do vestuário, como sapatos. Ao contrário das pobrezas relativa e moderada, a miséria só ocorre em países em desenvolvimento. A pobreza moderada refere-se, em geral, a condições de vida em que as necessidades básicas são satisfeitas, mas com muita dificuldade. A pobreza relativa é, em geral, interpretada como sendo uma renda familiar abaixo de uma determinada proporção da renda média nacional. (Sachs apud Debone, 2016, p.10)
} 
A pobreza é comumente medida a partir do critério monetário, ou seja, através da renda anual de cada indivíduo, a renda per capita. "Atualmente, é considerado em situação de miséria quem vive com menos de U\$ 1,25 por dia, e em situação de pobreza quem vive com menos de U\$ 2,00 por dia”. (DEBONE, 2016, p. 9-10). Estes dados são expostos pelo Banco Mundial, criado com a finalidade de financiar o desenvolvimento, e que trata da pobreza apenas quanto ao aspecto econômico.

A mensuração da pobreza somente a partir do índice pecuniário sofre inúmeras críticas, pois torna-se imprescindível a especificação de outros indicadores capazes de englobar situações sociais distintas que possam alcançar a realidade social. "Precisamos ampliar a questão da desigualdade para além da área enganosamente estreita em que ela está confinada, centrada estritamente no PIB ou na "renda per capita". (BAUMAN, 2010, p.82-83).

Basear-se apenas no salário mínimo e seus múltiplos é bastante usual na análise do desenvolvimento de determinada população. Talvez pela enorme facilidade com que se acham os dados estatísticos que versam sobre as linhas de pobreza e indigência. No entanto, diferentes territórios podem apresentar problemas e peculiaridades próprias, o Brasil é um bom exemplo, o nível de violência, analfabetismo, poluição, entre outros, varia de região para região.

Existe algo muito valioso e igualmente importante para avaliar o bem estar da sociedade, trata-se das liberdades substantivas preconizadas por Sen. A pobreza deve ser encarada essencialmente como a privação das capacidades basais, claro, não afastando a importância do critério econômico, posto que, para o autor este critério é importante para impulsionar o desenvolvimento.

1)A pobreza pode sensatamente ser identificada em termos de privação de capacidades; a abordagem concentra-se em privações que são intrinsecamente importantes (em contraste com a renda baixa, que é importante apenas instrumentalmente).

2)Existem outras influências sobre a privação de capacidades - e, portanto, sobre a pobreza real - além do baixo nível de renda (a renda não é o único instrumento de geração de capacidades).

3)A relação instrumental entre baixa renda e baixa capacidade é variável entre comunidades e até mesmo entre famílias e indivíduos (o impacto da renda sobre as capacidades é contingente e condicional). (SEN, 2010, p.120-121).

A pobreza como privação de liberdades pode ser retratada pelo aumento do desemprego, exclusão social, baixa escolaridade e a falta de uma saúde de qualidade por exemplo. As 


\section{REFORMA TRABALHISTA E NEGOCIAÇÃO COLETIVA: VIOLAÇÃO A DIREITOS FUNDAMENTAIS}

capacidades estão intimamente atreladas à obtenção de renda (como principal instrumento), pois esta acaba por proporcioná-las.

Um dos pontos cruciais para o aumento da qualidade de vida é o acesso à educação, já que ao obtê-la, poder-se-á superar a indigência, e assim sair da linha de pobreza. A expansão das capacidades humanas está relacionada ao desenvolvimento, e à liberdade de poder fazer escolhas que possam proporcionar uma vida plena e digna.

Vale considerar que, nem sempre a distribuição de rendas iguais podem melhorar igualmente a vida de dois indivíduos que pertencem a realidades diferentes. A qualidade de vida varia de acordo com as dificuldades enfrentadas por cada um, ou seja, deve-se considerar a diversidade do ser humano e suas reais necessidades.

Importante observar o pensamento de Veiga a respeito do crescimento econômico do país e da aplicação de políticas públicas destinadas tanto à educação como a serviços de saúde: "A qualidade de vida pode ser muito melhorada, a despeito dos baixos níveis de renda, mediante um programa adequado de serviços sociais”. (VEIGA, 2010, p.41).

O fato de uma pessoa não conseguir interagir, ou melhor, inserir-se no próprio meio social reflete a interação existente entre a cultura e a supressão econômica. Veiga, através de suas palavras, denota esta relação:

\footnotetext{
Apesar de a pobreza ser uma ideia essencialmente econômica, ela não pode ser devidamente entendida sem sua dimensão cultural. E foi o próprio Adam Smith quem primeiro estabeleceu essa estreita ligação entre privação cultural e pobreza econômica. Não disse apenas que a pobreza assume a forma bruta de fome e privação física, mas também que ela pode surgir nas dificuldades que alguns segmentos encontram para participar da vida social e cultural da comunidade. A lista de mercadorias que contam como "necessidades" não são independentes, segundo Smith, das exigências da cultura local. Para ele, os chamados "bens de primeira necessidade" não são aqueles indispensáveis para o sustento, mas todos os que o país considera indigno que alguém não possua. Quando o hábito fez com que, na Inglaterra, os sapatos de couro se tornassem uma necessidade, qualquer pessoa digna passou a ter vergonha de aparecer sem eles em público. (VEIGA, 2010, p.46).
}

Ressalta-se que, cada sociedade possui as próprias convicções no que diz respeito à conexão entre cultura e pobreza. A relatividade predominante em países ricos vai além da obtenção do mínimo vital, é mais uma questão de aceitabilidade dentro do grupo social que fere a dignidade humana. "A concepção relativa diz que saber se a dignidade humana foi violada é uma questão de proporcionalidade". (ALEXY, 2015, p.14). 


\section{DIGNIDADE HUMANA}

O período da Segunda Guerra Mundial foi avultado por momentos trágicos e atrocidades diversas provenientes de regimes totalitários. A dignidade humana era violada constantemente. A partir do pós guerra, inicia-se um novo momento histórico, onde o ser humano passa a ser compreendido como sujeito digno de proteção. Surge então, a Organização das Nações Unidas (ONU), com o objetivo de promover a paz, unir os povos para priorizar a proteção dos direitos humanos.

Com isto, em 1948, foi criada a Declaração Universal dos Direitos Humanos (DUDH) para por em prática a proteção da dignidade humana. Portela afirma que: "Na atualidade, há um número significativo de tratados de direitos humanos em vigor, com um vasto rol de direitos consagrados abrangendo uma grande amplitude de temas”. (PORTELA, 2011, p. 705).

A dignidade humana, como princípio fundamental, passou a ser o tema central, na elaboração dos textos constitucionais. A constituição de 1988 aponta, em seu artigo primeiro, que o Estado Democrático de Direito apresenta como um de seus fundamentos, presente no inciso terceiro, a promoção do princípio da dignidade humana considerada a raiz e o vetor de todos os direitos.

\footnotetext{
A Declaração de 1948 introduz a concepção contemporânea de direitos humanos, marcada pela universalidade e indivisibilidade desses direitos. Universalidade porque a condição de pessoa é o requisito único e exclusivo para a titularidade de direitos, sendo a dignidade humana o fundamento dos direitos humanos. (PIOVESAN, 2014, p.52).
}

Tratar sobre o princípio da Dignidade Humana nos leva a apreciar o pensamento filosófico revolucionário de Kant. Sua obra volta-se para a compreensão da moral, e assim, o autor ressalta que devemos agir sempre alicerçados na razão, posto que é esta racionalidade que nos torna diferentes dos demais seres e nos concede a autonomia da vontade.

$\mathrm{O}$ ordenamento jurídico tem por finalidade o ser humano, pois este encontra-se acima de qualquer interesse. Desta forma, interpreta-se que o homem não pode ser considerado como meio, mas sim, como "fim em si mesmo" (como evidencia o autor). Evidencia-se então a concepção de que a dignidade é inalienável.

No reino dos fins, tudo tem ou um preço ou uma dignidade. Quando uma coisa tem preço, pode ser substituída por algo equivalente; por outro lado, a coisa que se acha

Rev. de Direito Sociais e Políticas Públicas | e-ISSN: 2525-9881| Maranhão | v. 3 | n. 2 | p. 1 - 17 | Jul/Dez. 2017. 
acima de todo preço, e por isso não admite qualquer equivalência, compreende uma dignidade. (KANT, 2004, p.65).

O princípio da dignidade humana tem por escopo tornar efetivos os direitos inerentes a toda pessoa humana, compelindo o Estado para que este assuma a posição de garantidor, deste modo, serão instituídas medidas que salvaguardem tais direitos.

Sobre o assunto dispõe Sarlet (2001, p. 60):

Temos por dignidade da pessoa humana a qualidade intrínseca e distintiva de cada ser humano que o faz merecedor do mesmo respeito e consideração por parte do Estado e da comunidade, implicando, neste sentido, um complexo de direitos e deveres fundamentais que assegurem a pessoa tanto contra todo e qualquer ato de cunho degradante e desumano, como venham a lhe garantir as condições existenciais mínimas para uma vida saudável, além de propiciar e promover sua participação ativa corresponsável nos destinos da própria existência e da vida em comunhão dos demais seres humano.

Este conceito afirma ser a dignidade humana uma qualidade peculiar, que pertence somente ao ser humano, por isso cada um se reconhece no outro, devendo lutar pelos mesmos ideais e se contrapor a qualquer ato aviltante capaz de minorar a condição humana.

A dignidade predomina tanto no plano interno, nacional, como no âmbito internacional, reafirmada através de tratados internacionais.

Ao incorporar uma visão cosmopolita, ou seja, que entre os seres humanos não há qualquer distinção de valor, a constituição brasileira de 1988 consagra em seu artigo quinto um rol de direitos humanos com características de cláusula pétrea.

Além disso, merece destaque a Emenda Constitucional n. 45 de 2004 ao elencar que os tratados e convenções internacionais que versam sobre direitos humanos, aprovados em ambas casas, em dois turnos e 3/5 dos votos de seus membros serão igualados à status de emenda constitucional, ou seja, concedeu-lhes hierarquia constitucional.

Neste contexto, o Brasil, ao assinar os tratados que compreendem a valoração dos direitos humanos, se compromete a realizá-los. A erradicação da pobreza, para muitos uma utopia, é uma tarefa árdua, mas que deve ser levada em consideração a todo custo, pois a pobreza aniquila a dignidade humana. Vários programas são desenvolvidos para alcançar tal fim, a implementação do Programa de Bolsa Família é um dos principais exemplos. 


\subsection{Mínimo Existencial e Direitos Sociais}

O Mínimo Existencial originou-se na Alemanha, em 1953, e ganhou verdadeiro destaque na década de 1990, quando foi integrado às decisões jurisprudenciais. "[...] pelo mínimo entende-se o conjunto de condições elementares ao homem, como forma de assegurar sua dignidade”. (LAZARI, 2012, p. 102). Por esta compreensão, as condições necessárias à sobrevivência do ser humano encontram-se intimamente ligadas ao princípio da Dignidade Humana.

O Mínimo Vital deve ser entendido como um núcleo de direitos sociais imprescindíveis à existência do homem. A falta de alimento, de assistência médica e outras necessidades podem desencadear uma série de doenças que comprometem a vida. Na verdade é uma questão de sobrevivência.

Quanto à natureza jurídica de tal instituto, há bastante divergência doutrinária. Há quem alegue ser um princípio, outros relatam ser um regra e uma terceira corrente entende tratar-se de um valor. Neste sentido esclarece Torres:

\footnotetext{
O mínimo existencial não é um valor nem um princípio jurídico, mas o conteúdo essencial dos direitos fundamentais. Nada obstante está impregnado pelos valores e princípios jurídicos os mais relevantes. O mínimo existencial não é um valor, por não possuir a generalidade e a abstração de ideias como as de liberdade, justiça e igualdade. Além disso, o mínimo existencial pode se traduzir, para a sua garantia, em regra jurídica, o que jamais acontece com os valores. Mas o mínimo existencial se deixa tocar e imantar permanentemente pelos valores da liberdade, da justiça, da igualdade e da solidariedade. O mínimo existencial também não é princípio jurídico, por não exibir as principais características dos princípios, que são as de ser objeto de ponderação e de valer prima facie. De feito, o mínimo existencial não pode ser ponderado e vale definitivamente porque constitui o conteúdo essencial dos direitos fundamentais, que é irredutível por definição e insuscetível de um só pensamento. O mínimo existencial é regra, porque se aplica por subsunção, constitui direitos definitivos e não se sujeita à ponderação. (TORRES, 2008, p. 316).
}

O fato é que os bens que compõem o Mínimo Existencial não são facilmente mensurados, na maioria das vezes é o judiciário que os delimita, pois são bastante abrangentes e variáveis, haja vista tratar-se de aspectos qualitativos e não meramente quantitativos. Encontram-se relacionados aos direitos sociais previstos na Lei Fundamental pátria.

Os programas de transferência de renda desenvolvidos pelo governo federal visam oferecer uma renda à população mais carente no sentido de assegurar-lhe uma assistência básica. Assinala Debone (2016, p. 83): “[...] é significativo atenuar a pobreza dos países pobres ao 


\title{
REFORMA TRABALHISTA E NEGOCIAÇÃO COLETIVA: VIOLAÇÃO A DIREITOS FUNDAMENTAIS
}

menos por um motivo: para mantê-las em níveis que não impeçam o consumo básico por parte de sua população".

As metas governamentais devem priorizar o bem estar social, direcionar o orçamento para execução de políticas públicas voltadas à saúde, educação e assistência aos marginalizados. Neste sentido preconiza Bercovici:

\begin{abstract}
A fixação constitucional dos objetivos da República no art. 3 insere-se neste contexto de legitimação do Estado pela capacidade de realizar fins predeterminados, cuja realização se dá por meio de políticas públicas e programas de ação estatal. O próprio fundamento das políticas públicas, segundo Maria Paula Dallari Bucci, é a exigência de direitos sociais, que se concretizam através de prestações positivas do Estado, [...]. (BERCOVICI, 2005, p.107).
\end{abstract}

É cediço na literatura o entendimento de que o Estado é incumbido de promover o bem estar social. Esta função é posta em prática através das políticas públicas, em diferentes setores como educação, saúde, moradia, segurança pública, promoção de empregos, entre outros.

A constituição brasileira revela, em seu corpo normativo, diversos direitos sociais essenciais, os quais são usados como base para a composição do patamar mínimo essencial à sobrevivência do ser humano com dignidade. Sobre direitos sociais dispõe Silva (2014, p. 287):

\footnotetext{
Assim, podemos dizer que os direitos sociais, como dimensão dos direitos fundamentais do homem, são prestações positivas proporcionadas pelo Estado direta ou indiretamente, enunciadas em normas constitucionais, que possibilitam melhores condições de vida aos mais fracos, direitos que tendem a realizar a igualização de situações sociais desiguais. São, portanto, direitos que se ligam ao direito de igualdade $[\ldots]$.
}

Os direitos sociais foram conquistados após inúmeros movimentos reivindicatórios, inicialmente aplicados pela constituição Mexicana de 1917 e pela constituição de Weimar na Alemanha em 1919 e ganharam força no decorrer do século XX. Foram reconhecidos na esfera internacional com a Declaração Universal dos Direitos Humanos e pelo Pacto Internacional dos Direitos Econômicos, Sociais e Culturais.

Estes direitos tomaram proporção universal. Constituem o núcleo da cidadania e baseiam-se no princípio transcendental da Dignidade Humana. O Estado ficou incumbido de garantir esses direitos e proteger os desamparados.

Os direitos sociais, no quadro jurídico-político atual, concretizam a obrigação do Estado de controlar os riscos do problema da pobreza, que não podem ser atribuídos

Rev. de Direito Sociais e Políticas Públicas| e-ISSN: 2525-9881| Maranhão | v. 3 | n. 2 | p. 1 - 17 | Jul/Dez. 2017. 
exclusivamente aos próprios indivíduos, restituindo um status mínimo de satisfação das necessidades pessoais. Os direitos sociais, econômicos e culturais constituem, junto com as liberdades civis e políticas, o acesso a essa dimensão maior da liberdade. (BARRETTO, 2013, p. 220).

O país se desenvolve quando seu povo é amparado e tem seus direitos sociais garantidos. “[...]direitos sociais, que se realizam pela execução de políticas públicas, destinadas a garantir amparo e proteção social aos mais fracos e mais pobres[...]”. (COMPARATO, 2013, p. 78).

O que se coloca em pauta é a preocupação com a promoção dos direitos sociais em países emergentes. No caso do Brasil, que suporta um momento de crise econômica bastante contundente, é evidente que com esse enfraquecimento econômico restam comprometidos os mecanismos que visam proporcionar os direitos sociais, haja vista a falta de recursos para financiá-los. O Estado, por vezes, alega insuficiência de recursos para implementação das prestações estatais imperativas para a eficácia dos direitos econômicos, sociais e culturais.

Cumpre, desta forma, destacar o instituto da Reserva do Possível, que se coloca como um argumento de defesa do Estado e que ocasiona limitação à promoção dos direitos sociais.

Assim, faz-se necessária a comprovação da carência de recursos de acordo com o seu orçamento, ou seja, o ônus de provar a Reserva do Possível é indubitavelmente do Estado. Nesta direção suscita Lazari (2012, p.59): “o ônus de provar a insuficiência orçamentária cabe exclusivamente ao Estado".

O judiciário deve averiguar as demandas formuladas diante deste embate entre o Estado e os interesses da coletividade. Assim, a solução deve ser tomada levando-se em consideração a Equidade. Nas palavras de Portela "A Equidade é a aplicação de considerações de justiça a uma relação jurídica, quando não exista norma que a regule ou quando o preceito cabível não é eficaz para solucionar". (PORTELA, 2011, p. 77).

A decisão formulada neste tipo de demanda é bastante delicada. Vale lembrar que, assegurar o Mínimo Existencial é função primária do Estado. Embora perfeitamente legal, o instituto da Reserva do Possível não pode ser utilizado como forma de abster-se do compromisso com a sociedade.

Como forma de preservar a integridade física e moral do seu povo, o governo ao delimitar o direcionamento dos recursos públicos deve priorizar a faixa mínima de direitos que proporcionam uma vida digna aos menos favorecidos. 
De acordo com um relatório emitido pela Organização das Nações Unidas em 2012, que versa sobre a promoção e a proteção dos direitos civis, políticos, econômicos, sociais e culturais, assim como, o direito ao desenvolvimento, tem-se que:

\begin{abstract}
Dado os efeitos desproporcionais e devastadores das crises econômicas e financeiras sobre os grupos mais vulnerável à pobreza, os Estados devem prestar cuidados particulares em assegurar que as medidas de recuperação de crises, incluindo os cortes nas despesas públicas, não deneguem ou não infringem os direitos humanos desses grupos. As medidas a serem tomadas devem ser inclusivas e não discriminadoras. Elas devem assegurar o financiamento sustentável que possibilita aos sistemas de proteção social mitigar as desigualdades e garantir que os direitos dos indivíduos e dos grupos desfavorecidos e marginalizados não sejam afetados de forma desproporcional. (BRASILIA, 2012, p. 14).
\end{abstract}

A luta pelo redução das desigualdades sociais sempre será objetivo primordial do Estado Democrático de Direito.

\title{
3 PROGRAMA BOLSA FAMÍLIA (PBF)
}

O Programa Bolsa Família (PBF) é baseado na transferência de renda e foi criado em 2003, coordenado pelo Ministério do Desenvolvimento Social (MDS) e desenvolvido para amparar famílias desprovidas de condições mínimas para sobreviver, ou seja, enquadradas em situação de pobreza e pobreza extrema.

Diante de tal vulnerabilidade, o Governo Federal determinou que as famílias cuja soma de toda a renda mensal per capita não ultrapassasse oitenta e cinco reais, seriam beneficiadas pelo programa. $\mathrm{O}$ valor pecuniário a ser percebido varia de acordo com o número de pessoas que compõem a família, crianças, adolescentes, gestantes e nutrizes.

De acordo com a lei n. 10.836 de 2004, em seu parágrafo único, o PBF decorreu da unificação de outros programas préexistentes como, por exemplo, o Bolsa Escola, o Bolsa Alimentação e o Programa Auxílio Gás. Em vez de a família carente realizar vários cadastros para obter uma melhor assistência, ela só precisa fazer isso uma única vez, através do Cadastro Único (CADÚNICO). Tornou-se vantajoso também por propiciar uma fiscalização mais precisa, pois dificulta a ocorrência de possíveis fraudes.

Assim, o Cadastro Único é considerado um mecanismo qualificado e essencial para a promoção da inclusão social. Utilizado para reconhecer as famílias mais vulneráveis e inseri- 
las no PBF, através de informações que caracterizam a situação socioeconômica. Para tanto, é mister a comprovação da baixa renda.

Esta seleção, através de informações de dados, é bastante criteriosa para evitar injustiças, já que busca priorizar àquelas pessoas mais desfavorecidas. Após essa triagem, essas famílias irão dispor de um cartão, expedido pela Caixa Econômica Federal, para sacar o valor.

No momento em que se encontrarem cadastradas, os dados preenchidos e que identificam a família ficam em sigilo, somente manipulados para a produção de pesquisas estatísticas e gestão de políticas públicas.

A transferência de renda para as mãos dos economicamente vulneráveis não se deu de forma direta e incondicional. Pelo contrário, o governo fez algumas exigências em troca do benefício, as chamadas condicionalidades.

Através das condicionalidades, o governo Federal buscou melhorar tanto a saúde como a educação, contribuindo desta forma para o desenvolvimento do povo. Portanto, as crianças e adolescentes, com idade entre seis e quinze anos precisam estar devidamente matriculadas em instituições de ensino.

Apenas a matrícula não é suficiente, exige-se ainda, uma dada frequência mínima escolar. Esta efetiva frequência escolar faz com que diminua o número de crianças e adolescentes pedintes nas ruas, resultando consequentemente na redução do trabalho infantil.

As condicionantes ligadas à saúde promovem o acompanhamento médico de gestantes e crianças, que devem comparecer à unidade de saúde periodicamente. Com isto, há uma redução da mortalidade e controle de doenças, além de ocorrer uma maior interação da população com os programas e campanhas realizadas pelo Ministério da Saúde, como por exemplo, o incentivo ao aleitamento materno. O intuito é apensar os pobres na admissão e efetivação dos direitos sociais.

O procedimento normal é que, a cada dois anos, os beneficiários devam fazer o recadastramento do PBS o mais breve possível para evitar que o pagamento seja bloqueado.

De acordo com as informações expostas pelo Ministério do Desenvolvimento Social (MDS) no Portal Brasil, os dados colhidos da revisão cadastral de 2015 revelam o número de famílias, por região, que melhoraram as condições de vida. Toma-se para análise a Região nordeste: em março de 2016, o programa beneficiou quase sete milhões de famílias, considerando-se uma média de quatro pessoas por família, vinte e oito milhões de pessoas foram beneficiadas. Foram convocadas para participar da revisão mais de novecentas e sessenta 


\section{REFORMA TRABALHISTA E NEGOCIAÇÃO COLETIVA: VIOLAÇÃO A DIREITOS FUNDAMENTAIS}

e cinco mil famílias nordestinas, número este que representa $33 \%$ de famílias cadastradas no sistema. Destas, 4,5\% obtiveram melhoria financeira e saíram do programa. As regiões norte e nordeste, comparadas às demais, apresentaram o menor percentual de famílias que saíram do programa após o recadastramento de 2015, o que retrata a persistente desigualdade regional. (BRASIL, 2015).

O artigo terceiro, inciso três da Constituição Federal de 1988, preconiza a erradicação da pobreza, assim como a redução das desigualdades regionais. No entanto, a má distribuição de renda no país ainda vislumbra uma realidade cruel.

Torna-se preciso levar a sério esta questão, Guerra adverte que: “[...] a pobreza, tal como mencionado anteriormente, carrega consigo muito mais as motivações relacionadas à ausência de distribuição de renda do que a escassez em si mesma”. (GUERRA, 2013, p.318).

O nordeste é uma região que concentra um grande número de pessoas necessitadas de recursos básicos para viver. O Programa Bolsa família, a partir das requisições, ou melhor, das condicionantes, contribui para o aumento do índice de desenvolvimento humano, haja vista um maior número de crianças e adolescentes frequentarem a escola, ou seja, o número de analfabetos reduz-se satisfatoriamente. Além disso, a participação em campanhas de saúde e acompanhamento médico melhora a perspectiva de vida.

A respeito do relatório emitido pelo MDS sobre o índice de desenvolvimento humano (IDH):

\footnotetext{
Relatório de Desenvolvimento Humano 2015- Trabalho para o Desenvolvimento Humano, do Programa das nações Unidas para o Desenvolvimento (Pnud), destaca a importância do Bolsa Família para o crescimento do índice de desenvolvimento humano (IDH) obtido pelo Brasil nos últimos anos. O estudo divulgado nesta segunda-feira (14), mostra que o IDH brasileiro alcançou o nível 0,755 em 2014, em uma alta de pouco mais de 10,5\% ante o índice de 0,683, em 2000.

O Pnud cita, nesse contexto, o Bolsa Família como fator importante para o avanço do IDH e aponta que o programa é exemplo a ser copiado por outros países. [...] $\mathrm{O}$ programa de complementação de renda, segundo o relatório, teve efeito na quedo do Índice de Pobreza Multidimencional, que considera, além da renda, as condições de saúde, educação e padrão de vida. De 2006 a 2014, o índice teve redução de 27,5\% passando de $4 \%$ para 2,9\% de brasileiros nesta condição. (BRASIL, 2015,p. 2)
}

Observa-se que, o Bolsa Família, a partir da análise do IDH verificado em 2015 neste relatório, ajudou muitas pessoas a melhorarem a qualidade de vida. E com isso, o PBF é apontado como exemplo a ser seguido em outros países. Neste diapasão, ressalta Garcia: 
O reconhecimento definitivo do efeito do Bolsa Família ocorreu no segundo semestre de 2014. Nesse ano, a Organização das Nações Unidas para a Alimentação e a Agricultura (FAO) divulgou novo relatório com o Mapa Mundial da Fome e, pasmem para os incrédulos, o Brasil não constatava mais nessa vergonhosa geografia. Infelizmente não significa a completa eliminação dessa chaga do cenário brasileiro. A instituição considera superada a questão da fome quando o índice de insegurança alimentar atinge menos de $5 \%$ da população do país. (GARCIA, 2016, p.15).

O Instituto Brasileiro de Geografia e Estatística (IBGE) comprova que entre os anos de 2000 e 2015 houve uma queda significativa da taxa de mortalidade no Brasil. Em 2000, a cada mil crianças nascidas vivas a taxa era de aproximadamente trinta, e em 2015 essa taxa ficou em torno de quinze, ou seja, caiu pela metade.

Ademais, uma outra pesquisa realizada aponta para a queda da mortalidade no país relacionando-a com o PBS:

Pesquisa publicada na revista The Lancet, edição de maio de 2013, aponta que o programa contribuiu para redução de 17\% na mortalidade infantil entre 2004 e 2009. A queda relacionada à segurança alimentar foi maior ainda: $65 \%$ das mortes por desnutrição e 53\% dos óbitos causados por diarreia. (GARCIA, 2016, p.59).

Essa decrescente mortalidade infantil está relacionada ao PBS pelo fato de este exigir que as gestantes tenham acompanhamento pré- natal periodicamente e que seja comprovada a vacinação infantil. Estas informações são devidamente registradas no sistema.

Apesar de este programa amenizar a pobreza, aliviar os efeitos desastrosos da fome e da miserabilidade, a desigualdade social é persistente.

A má distribuição de renda no país é explicada pela sua própria história, mas as lutas sociais pregressas tiveram efeitos extraordinários no avanço dos direitos sociais. Isto quer dizer que, mesmo que ao Estado caiba a tarefa de promover a inclusão social através de políticas públicas, a sociedade deve fazer o seu papel, ou seja, participar ativamente na busca da realização de seus direitos.

\section{CONSIDERAÇÕES FINAIS}

Refletir sobre o tema pobreza é refletir sobre o próprio sentido da vida, pois ela fere a dignidade humana, que é o bem mais precioso.

A dignidade, essência de todo ser humano, está atrelada à liberdade, à capacidade de seguir seus preceitos, ou seja, guiar-se pela própria vontade. Neste pensar, é incontestável a 


\section{REFORMA TRABALHISTA E NEGOCIAÇÃO COLETIVA: VIOLAÇÃO A DIREITOS FUNDAMENTAIS}

ideia de que a dignidade não pode ser vendida ou comprada e possui seu caráter universal, posto que reconhecida como núcleo e alicerce dos demais direitos.

Diante das informações reveladas pelo Ministério do Desenvolvimento Social e combate à fome, tem-se que, os dados referentes à revisão cadastral de 2015 constataram um total de 810.282 famílias beneficiárias do Programa Bolsa Família que melhoraram a qualidade de vida e com isso saíram do programa, isto representa $6 \%$ dos convocados de todo o Brasil, o que demonstra um avanço na inclusão social.

Outrossim, as condicionantes impostas pelo PBF são estratégias idealizadas exatamente para garantir a efetividade do programa, para que este não se limite apenas a transferir a renda, mas também, promover o acesso direto ao sistema único de saúde (SUS) bem como a permanência de crianças e adolescentes nas escolas.

É inquestionável o fato de ser a educação a principal solução para que o desenvolvimento social seja alcançado, através dela, o analfabetismo pode ser abolido, as pessoas se tornam mais qualificadas o que facilita a inserção no mercado de trabalho. Além disso, tornam-se cidadãos mais conscientes de seus direitos e deveres.

Com relação à saúde, o pré-natal das gestantes, assim como o acompanhamento da carteira de vacinação infantil representa um monitoramento que resulta na queda da mortalidade infantil. A pesquisa realizada pelo IBGE comprova a queda da mortalidade infantil de aproximadamente $50 \%$ entre os anos de 2000 e 2015.

Diante das informações levantadas, comprova-se que o PBF tem representado uma solução substancial às famílias que vivem em condições de vulnerabilidade, o que comprova sua efetividade no combate à pobreza. No entanto, o Estado deve, como promotor dos direitos humanos, priorizar políticas públicas que complementem o $\mathrm{PBF}$, tais como o incentivo à criação de empregos e propiciar habitação básica que possa assegurar a todos os brasileiros uma vida digna.

Por fim, é válido lembrar que, o crescimento econômico é imprescindível para o país alcançar a inclusão social, com ele o Estado pode financiar as políticas públicas necessárias no combate à pobreza, principalmente ao criar oportunidades sociais. 


\section{REFER̂̂ENCIAS:}

ALEXY, Robert; BAEZ, Narciso Leandro Xavier; DA SILVA, Rogério Luiz Nery. (Org). Dignidade humana, direitos sociais e não-positivismo incluso. 1. ed. Florianópolis: Qualis, 2015.

BARRETTO, Vicente de Paulo. O Fetiche dos direitos humanos e outros temas. 2. ed. rev. e aum. Porto Alegre: Livraria do advogado Editora, 2013.

BAUMAN, Zygmunt. Vida a Crédito. Trad. Alexandre Werneck. Rio de Janeiro: Zahar, 2010.

BERCOVICI, Gilberto. Constituição econômica e desenvolvimento: uma leitura a partir da Constituição de 1988. 1. ed. São Paulo: Malheiros, 2005.

BRASIL. Constituição (1988). Emenda constitucional no 9, de 9 de novembro de 1995. Lex: legislação federal e marginália, São Paulo, v. 59, p. 1966, out./dez. 1995.

Cidadania e Justiça. Bolsa Familia melhorou a vida de mais de 604 mil lares brasileiros em 2015. Disponível em: <http://www.brasil.gov.br/cidadania-e-justica/2016/04/bolsafamilia-melhorou-a-vida-de-mais-de-604-mil-lares-brasileiros-em-2015>. Acesso em: 03 Ago. 2017

. Bolsa Familia é destaque relatório internacional. Disponível em:

<http://www.brasil.gov.br/cidadania-e-justiça/2015/12/bolsa-familia-e-destaque-relatoriointernacional-1>. Acesso em: 02 de Ago.2017.

BRASILIA. Nações Unidas. Conselho de Direitos Humanos. Promoção e proteção de todos os direitos humanos, direitos civis, políticos, econômicos, sociais e culturais, inclusive o direito ao desenvolvimento.Brasília, 2012. Disponível em:

<http://www.usjt.br/arq.urb/arquivos/abntnbr6023.pdf >. Acesso em: 05 Ago. 2017.

COMPARATO, Fábio Konder. A afirmação histórica dos direitos humanos. 8. ed. São Paulo: Saraiva, 2013.

DEBONE, Rebecca Rafart de Seras Hoffmann. Pobreza Extrema: violação dos direitos humanos?. Belo Horizonte: Arraes Editores, 2016.

GARCIA, Roseli. No rastro do Bolsa Família. 1. ed. São Paulo: Chiado Editora, 2016.

GUERRA, Sidney. Direitos Humanos: curso elementar. 1a ed. São Paulo: Saraiva, 2013. INSTITUTO BRASILEIRO DE GEOGRAFIA E ESTATÍSTICA - IBGE. Taxa de mortalidade infantil. Disponível em : <http://brasilemsintese.ibge.gov.br/populacao/taxas-demortalidade-infantil.html>. Acesso em: 03 Ago. 2017.

KANT, Immanuel. Fundamentação da metafísica dos costumes e outros escritos. Tradução Leopoldo Holzbach. São Paulo: Martin Claret, 2004. 
DE LAZARI, Rafael José Nadim. Reserva do possível e mínimo existencial. 1. ed. Curitiba: Juruá, 2012.

PIOVESAN, Flávia. Temas de direitos humanos. 7. ed. São Paulo: Saraiva, 2014.

PORTELA, Paulo Henrique Gonçalves. Direito internacional público e privado. 3. ed. Bahia: Juspodivm, 2011.

SARLET, Ingo Wolfgang. A eficácia dos direitos fundamentais. 2. ed. Porto Alegre: Livraria do Advogado, 2001.

SEN, Amartya. Desenvolvimento como liberdade. Tradução Laura Teixeira Motta. São Paulo: Companhia das letras, 2010.

DA SILVA, José Afonso. Curso de direito constitucional positivo. São Paulo: Malheiros, 2014.

TORRES, Ricardo Lobo. O Mínimo existencial como conteúdo essencial dos direitos fundamentais. In: . SOUZA NETO, Claudio Pereira de.; SARMENTO, Daniel (Org). Direitos Sociais: Fundamentos, judicialização e direitos sociais em espécie. Rio de Janeiro: Lumen Juris, 2008.

DA VEIGA, José Eli . Desenvolvimento sustentável: o desafio do século XXI. Rio de Janeiro: Garamond, 2010. 